\title{
Studies on Physico Chemical Parameters of 5 water bodies of Ranchi (Jharkhand)
}

\author{
Mouli Chakroborty, Amit Kumar Bundela, Rashika Agrawal, Benoy Sabu, Manoj \\ Kumar*, Bharti \\ Singh Raipat, Priyanka Saha, Pipas Kumar
}

Department of Zoology, St. Xavier’s College, Ranchi, dr17mk@gmail.com

\begin{abstract}
Aquatic ecosystems are particularly vulnerable to environmental change and many are, at present, severely degraded. The availability of good quality water is an indispensable feature for preventing disease and improving quality of life. The physicochemical properties will also help in the identification of sources of pollution, for conducting further investigations on the ecobiological impacts and also for initiating necessary steps for remedial actions in case of polluted water bodies. Therefore, the nature and health of any aquatic community are an expression of quality of the water. The present study has been undertaken to evaluate physico-chemical parameters $(\mathrm{pH}$, alkalinity, dissolved oxygen, free carbon dioxide, sulphate content, chloride content and phosphate content) in 5 water bodies in and around Ranchi - Patratu Dam, Kanke dam, Dhruwa dam, Ranchi Lake, Line-tank Lake.
\end{abstract}

Keywords: $\mathrm{pH}$, dissolved oxygen, free carbon dioxide, sulphate content, chloride content, phosphate content, alkalinity.

\section{INTRODUCTION}

Water is an indispensable resource for the world economy as well as a precondition for human, animal and plant life, as there can be no stability of health and wellbeing without safe and adequate water supply. Water is a universal solvent dissolving a number of substances that it comes in contact with. However, water for human consumption and other domestic purposes should be free from disease causing organisms, poisonous substances and excessive amounts of mineral and organic matter. It should also be free from colour, turbidity, taste and odour (RimRukeh, 2013). Water quality refers to all physical, chemical and biological characteristics of water. It is determined by various physical, chemical and biological parameters of water bodies. Water quality plays an important role in the growth and survival of aquatic organisms. Relationship between water quality and aquatic productivity is a pre-requisite for obtaining optimum growth and production. For example, water used for aquaculture would not give the desired production unless the prevailing water quality parameters are optimum for the organism under culture. Study of physico-chemical parameters of an aquatic ecosystem is basic for understanding its biological productivity. Although each factor plays its individual role, but it is the synergistic effect of various parameters which determines the composition and productivity of the flora and fauna (Bisht et al., 2013). The present study was undertaken during the month of January, 2017 to determine the physico-chemical properties of 5 different water bodies of Ranchi - Patratu dam, Dhruwa dam, Kanke dam, Ranchi lake and Line-tank lake. Among various physicochemical factors, we are taking into consideration the ph, temperature, alkalinity, chloride content, sulphate content, dissolved oxygen, free carbon dioxide, nitrate content and phosphate content. 


\section{MATERIALS AND METHODS}

- pH (Potentia Hydrogenii): The $\mathrm{pH}$ of all the samples was determined using $\mu$ Controller based pH system (Systronics Type-362).

- Free Carbon dioxide: $100 \mathrm{ml}$ of sample was taken in a conical flask and phenolphthalein indicator was added. The colour change indicates absence of free $\mathrm{CO}_{2}$. In case the sample remains colourless, then the samples were titrated with $\mathrm{NaOH}(0.05 \mathrm{~N})$ solution. The appearance of pink colour demarcated the end of titration. The volume of $\mathrm{NaOH}$ consumed for titration was recorded.

The concentration of free $\mathrm{CO}_{2}$ was determined by using the following formula

$$
\text { Free CO2 }(\mathrm{mg} / \mathrm{L})=\frac{\mathrm{ml} \text { of } \mathrm{NaOH} \times 1000 \times 44}{\mathrm{ml} \text { of sample }}
$$

- Alkalinity: $100 \mathrm{ml}$ of sample was taken and methyl orange was used as indicator and then titrated with $0.1 \mathrm{~N} \mathrm{HCl}$ till appearance of pink colour. The volume of $\mathrm{HCl}$ consumed for titration was recorded. The total alkalinity was determined using the following formula

$$
\text { Total alkalinity }(\text { as } \mathrm{CaCo} 3)=\frac{(\mathrm{ml} \times \mathrm{N}) \mathrm{HCl} \times \mathrm{Eq} . \text { Wt. of } \mathrm{CaCO}_{3} \times 1000}{\text { Vol.of water sample }}
$$

- Dissolve Oxygen: the amount of dissolved oxygen content was determined following Wrinkler's method. $250 \mathrm{ml}$ of sample was taken in a flask and $1 \mathrm{ml}$ of $\mathrm{MnSO}_{4} \cdot 4 \mathrm{H}_{2} \mathrm{O}$ and alkaline iodide well below the surface. Dark brown precipitate indicates good amount of $\mathrm{O}_{2}$ and light brown and brownish white precipitate indicates medium and little amount of oxygen. The bottle was shaken and allowed to stand for about 30 minutes. Then 1-2 ml of concentrated sulphuric acid was added. This solution was then titrated against $\mathrm{Na}_{2} \mathrm{~S}_{2} \mathrm{O}_{3}(0.025 \mathrm{~N})$ till pale straw colour was obtained. Then starch indicator was added which turned the solution blue black and it was again titrated till the colour disappeared. The amount of dissolved oxygen was determined using the following formula

$$
\text { Amount of dissolved } \mathrm{O} 2=4 \times \text { vol of } \mathrm{Na}_{2} \mathrm{~S}_{2} \mathrm{O}_{3}
$$

- Chloride content: $20 \mathrm{ml}$ of water sample was taken in a conical flask and $1 \mathrm{ml}$ of $\mathrm{K}_{2} \mathrm{CrO}_{4}(2 \%)$ was added as an indicator. Then the solution was titrated with Silver nitrate $(0.02 \mathrm{~N})$ solution. The appearance of brick red colour marked the end of titration. The volume of Silver nitrate consumed during titration was recorded. The chloride content was determined using the following formula.

$$
\text { Chloride content }(\mathrm{mg} / \mathrm{L})=\frac{(\mathrm{ml} \times \mathrm{N}) \text { of } \mathrm{AgNO}_{3} \times 35.5 \times 1000}{\text { volume of water sample }}
$$

- Sulphate Content: The sulphate content of water samples was determined using the colorimetric method.

Conditioning reagent was prepared by mixing $25 \mathrm{ml}$ of glycerol and $15 \mathrm{ml}$ of Conc. HCL with $50 \mathrm{ml}$ of 35\% isopropyl alcohol and $37.5 \mathrm{~g}$ of NaCL was dissolved in sufficient distilled water and mixed to this solution. The solution was then made to $250 \mathrm{ml}$ using distilled water.

Standard sulphate solution was prepared by dissolving $1.479 \mathrm{~g}$ anhydrous sodium sulphate in $1000 \mathrm{ml}$ distilled water. 
Four $100 \mathrm{ml}$ glass stoppered flasks were taken as standard and on as blank. $10 \mathrm{ml}$ of standard sulphate solution was added to $1^{\text {st }}$ flask, $20 \mathrm{ml}$ to $2^{\text {nd }}$ flask, $30 \mathrm{ml}$ to $3^{\text {rd }}$ flask, 40 $\mathrm{ml}$ to $4^{\text {th }}$ flask. In the flask serving as blank, only distilled water was taken. In five different beakers $20 \mathrm{ml}$ each of water sample from different water bodies was taken. $5 \mathrm{ml}$ of conditioning reagent was added to all the flasks except blank and volume was made upto $100 \mathrm{ml}$ with the help of distilled water. At the end a pinch of $\mathrm{BaCl}$ was added to all the flasks and beakers, and after letting the solutions to stand for 3-5 minutes, the turbidity of each standard and samples were measured by colorimeter at $420 \mathrm{~nm}$.

The absorbance data of blank and standards were used to plot the standard graph. The standard graph was plotted with the help of
Microsoft Excel, 2007 and the slope was determined. The intercept $\mathrm{C}$ was taken as 0 .

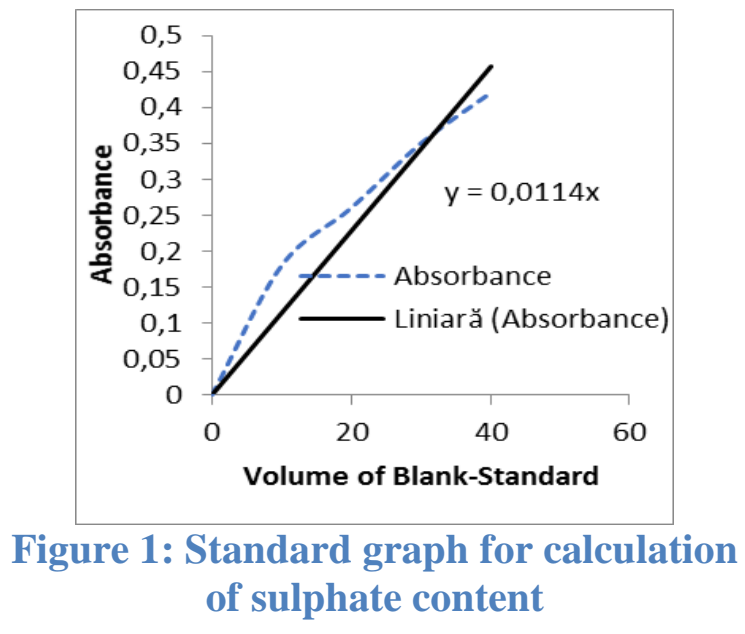

The sulphate content was determined using following model calculations $Y=m X+C$

Where $\mathrm{Y}=$ absorbance of the sample; $\mathrm{m}$ = slope; $\mathrm{X}=$ concentration of sample in $\mathrm{mg} ; \mathrm{C}=0$ (intercept)

$$
\text { Concentration of Sulphate }(\mathrm{mg} / \mathrm{L})=\frac{X \times 1000}{\mathrm{ml} \text { of sample taken }}
$$

- Phosphate content: $50 \mathrm{ml}$ of water sample was taken in a flask and phenolphthalein solution was added to it. Then $2 \mathrm{ml}$ of ammonium molybdate solution and $0.25 \mathrm{ml}$ of $\mathrm{SnCl}_{2} \cdot \mathrm{H}_{2} \mathrm{O}$ was mixed thoroughly and after 10 minutes, absorbance of each sample was measured at $690 \mathrm{~nm}$. The concentration of sample was determined by standard phosphate calibration curve.

$$
\mathrm{MgPO}_{4} \text { per } \mathrm{L}=\frac{\mathrm{MgPO}_{4} \text { from curve } \times 1000}{\text { ml of sample }}
$$

Standard curve for phosphate: different volumes $(1-10 \mathrm{ml})$ of standard phosphate solution in different beakers were taken and all diluted to $50 \mathrm{ml}$ with distilled water $(1 \mathrm{ml}$ of standard $\mathrm{PO}_{4}$ solution contains $0.05 \mathrm{mg}$ of $\mathrm{PO}_{4}$ ). Then $2 \mathrm{ml}$ of ammonium molybdate solution and $0.25 \mathrm{ml}$ stannous chloride solution were added and mixed thoroughly. The absorbance of each sample was measured at $690 \mathrm{~nm}$ and curve between optical densities and known amount of $\mathrm{PO}_{4}$ for each solution was drawn using Microsoft office Excel 2007. The concentration of phosphate in samples from water bodies was calculated using the standard curve with the help of function (=trend) in Microsoft office excel, 2007. 
Ammonium molybdate solution: $25 \mathrm{~g}$ of $\left(\mathrm{NH}_{4}\right)_{6} \mathrm{Mo}_{7} \mathrm{O}_{24} .4 \mathrm{H}_{2} \mathrm{O}$ was dissolved in 35 $\mathrm{ml}$ of distilled water and to this $62 \mathrm{ml}$ concentrated $\mathrm{H}_{2} \mathrm{SO}_{4}$ was added. The solution was then diluted with distilled water upto $200 \mathrm{ml}$.

\section{RESULTS AND DISCUSSION:}

The results of $\mathrm{pH}$, free carbon dioxide content, dissolved oxygen content, alkalinity, chloride content and sulphate content analysis is presented in figure 3-8 respectively.

The results of $\mathrm{pH}$ analysis (figure 3) ranged from 7.193 (Kanke dam) to 8.653 (Line tank lake). The $\mathrm{pH}$ of lakes and streams often changes during the day in response to photosynthetic activity. In ponds having poorly buffered (low alkalinity) waters, the $\mathrm{pH}$ may fall to approximately 7 in the early morning and increase to 9 or more in the afternoon (Boyd, 1990). Below a pH of 5.0, mortality occurs in some life stages of certain fish species, although some fishes can be acclimated to $\mathrm{pH}$ levels below 4.0. Nevertheless the primary productivity of freshwater ecosystems is reduced considerably below $\mathrm{pH}$ 5.0, which in turn, reduces the food supply for higher organisms (Alabaster and Lloyd, 1980). According to Utah State University, water quality standards, the $\mathrm{pH}$ range from $6.5-9.0$ is normal, any change below or above this range will prove harmful to the flora and fauna of the water bodies. In our study the $\mathrm{pH}$ values of different water bodies ranged from $7.141-8.653$ which is in the viable range.

The results of alkalinity (figure 6) test ranged from 15 (Line tank lake) to 40 (Dhurwa dam). Alkalinity is the name given to the quantitative capacity of an aqueous solution to neutralize an acid (WQA Glossary of terms, 2000). This is an expression of buffering capacity. Alkalinity is important for fish and aquatic life because it protects or buffers against rapid $\mathrm{pH}$

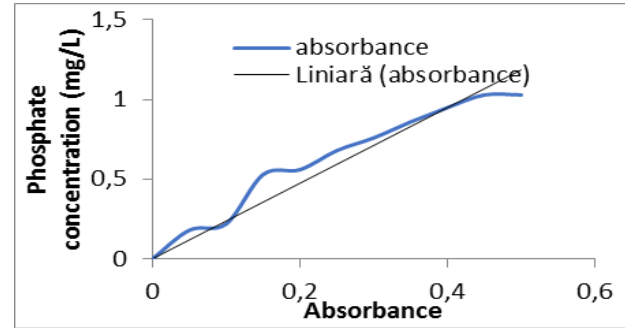

Figure 2: Standard calibration curve for Phosphate content

changes. Living organisms, specially aquatic life, function best in a $\mathrm{pH}$ range of $6.0-9.0$. alkalinity is a measure of how much acid can be added to a liquid without causing a large change in $\mathrm{pH}$. Thus the results of alkalinity test reflects the buffering capacity of water bodies which is high in dhurwa dam $(\mathrm{pH}$ 7.141) and lowest in line tank lake (ph 8.653).

The results of free $\mathrm{CO}_{2}$ analysis ranged from $7 \mathrm{mg} / \mathrm{L}$ (Line tank lake) to 28.6 $\mathrm{mg} / \mathrm{L}$ (Dhurwa dam). The free carbon dioxide released during respiration reacts with water producing carbonic acid and as a result $\mathrm{pH}$ is lowered. The results of free carbon dioxide analysis shows relation between the free carbon dioxide and $\mathrm{pH}$ of water bodies - Dhurwa dam have highest amount of free $\mathrm{CO}_{2}(28.62 \mathrm{mg} / \mathrm{L})$ has the lowest $\mathrm{pH}$ (7.141) and the Line tank lake having lowest free $\mathrm{CO}_{2}(7 \mathrm{mg} / \mathrm{L})$ has the highest $\mathrm{pH}$ (8.653). The date in table 1 (William and Robert, 1992) shows the relation between dissolved oxygen, free carbon dioxide and $\mathrm{pH}$ of water bodies.

Table 1: relationship between Dissolved $\mathrm{O}_{2}$, free $\mathrm{CO}_{2}$ and $\mathrm{pH}$ (adopted from William and Robert (1992)

\begin{tabular}{|l|l|l|}
\hline $\begin{array}{l}\text { DISSOLVED } \\
\text { OXYGEN }\end{array}$ & $\begin{array}{l}\text { FREE } \\
\text { CARBON } \\
\text { DIOXIDE }\end{array}$ & pH \\
\hline Increases & Decreases & Increases \\
\hline Decreases & Increases & Decreases \\
\hline
\end{tabular}

The results of dissolved $\mathrm{O}_{2}$ ranged from $10.05 \mathrm{mg} / \mathrm{L}$ (Kanke dam) to $14.3 \mathrm{mg} / \mathrm{L}$ (line tank lake). The results clearly is in agreement with the findings of William and Robert (1992) - depicted in table 1. 
The results of chloride content analysis ranged from $39.05 \mathrm{mg} / \mathrm{L}$ (Dhurwa dam) to $170.4 \mathrm{mg} / \mathrm{L}$ (line tank lake). Chloride enters the surface water from both natural and anthropotenic sources, such as run-off containing road de-icing salts, the use of inorganic fertilizers, landfill leachates, septic tank effluents, animal feeds, industrial effluents, irrigation drainage etc. chloride in water may be considerably increased by treatment processes in which chlorine or chloride is used (WHO, 2003). According to WHO (2003) a normal adult human body contains approximately $81.7 \mathrm{~g}$ chloride. On the basis of a total obligatory loss of chloride of approximately $530 \mathrm{mg} /$ day, a dietary intake for adults of $9 \mathrm{mg}$ of chloride per $\mathrm{kg}$ of body weight has been recommended (WHO, 2003). During water sample collection from Dhurwa dam and Kanke dam, we saw people fetching water for drinking. Which can have lethal impacts on individuals consuming water from these water bodies, as according to WHO (2003) , for an 18 year old human, a daily dietary intake of $45 \mathrm{mg}$ of chloride is sufficient, but consumption of water from these water bodies will introduce chloride in a concentration much higher above the normal level. The drinking of water containing high amounts of chloride has been linked to increased incidence of colon cancer, bladder cancer (EFS, 2010).

The results of sulphate content ranged from $87.7 \mathrm{mg} / \mathrm{L}$ (Patratu dam) to 614 $\mathrm{mg} / \mathrm{L}$ (Line tank lake). Sulphates and sulfuric asic products are used in the production of fertilizers, chemicals, dyes, glass, paper, soaps, textiles, fungicides, insecticides, astringents and emetics. They are also used in mining, wood pulp, metal and plating industries, in sewage treatment and in leather processing. (Greenwood and Earnshaw, 1984). Sulphates are discharged into water from industries such as kraft pulp, paper mills, textile mills and tanneries. According to GEMS/Water, a global network of water monitoring stations, the typical sulphate levels in fresh water are in the vicinity of 20 $\mathrm{mg} / \mathrm{L}$ and range from $0-630 \mathrm{mg} / \mathrm{L}$ in rivers,
2-250 mg/L in lakes and $0-230 \mathrm{mg} / \mathrm{L}$ in ground water (UNEP, 1990). Paterson et al. (1979) studied the impact of short term (28 days) exposure of sulphate in weanling pigs and reported no adverse effects other than diarrhea from drinking water containing $3000 \mathrm{mg}$ of sulphate per litre. Coccehetto and Levy (1981), Morris and Levy (1983) reported that ingestion of $8 \mathrm{~g}$ of sodium sulphate and $7 \mathrm{~g}$ of magnesium sulphate cause catharsis in adult males. Cathartic effects are commonly reported to be experienced by people consuming drinkingwater containing sulphate concentrations exceeding $600 \mathrm{mg} / \mathrm{L}$ (US DHEW, 1962). Dehydration was also reported by Fingl (1980) as a side-effect following ingestion of large amounts of sulphates.Thus the Line tank lake which shows the highest sulphate content $(614.03 \mathrm{mg} / \mathrm{L})$ indicates industrial pollution of the water body, making the water unfit for human and animal consumption. The water of Patratu dam shows lowest sulphate content, which demarcates that, there is no or little industrial pollution. And the water is safe for domestic purposes, human and animal consumptions.

The value of phosphate content in water bodies ranged from $0.0052 \mathrm{mg} / \mathrm{L}$ (Dhurwa dam) to $0.373 \mathrm{mg} / \mathrm{L}$ (Ranchi lake). Phosphorus is a vital nutrient for converting sunlight into usable energy, and essential to cellular growth and reproduction. Thus it fuels the algae growth. Phosphate are preferred for plant growth. As there is increase in phosphate concentration, eutrophication occurs, the algal population rises rapidly, and as the algae die and decompose, the process consumes oxygen. Without enough dissolved oxygen in water, fish and other organisms suffer and die (Minnesota Pollution Control Agency, 2008). Many bodies of fresh waters in Ranchi are currently experiencing increases of phosphates from outside sources. The increasing concentration of available phosphorus allows plants to assimilate more nitrogen before the phosphates are depleted. Thus if sufficient phosphates are available, elevated concentrations of nitrates will lead 
to algal blooms. The Ranchi lake shows highest phosphate concentration, which triggers periodic blooms.

CONCLUSION: The study suggests that still the larger water bodies away from main population of Ranchi is in good conditions as far as the parameters studied in this research work is considered. Almost all the parameters studied were in healthy concentration except the sulphate content which was high in line tank lake (614.03 $\mathrm{mg} / \mathrm{L}$ ) and moderately high in Ranchi lake. The study revealed that the Ranchi lake and Line tank lake is receiving industrial and domestic wastes. Proper planning of drainage system to prevent the waste water from reaching the water bodies should be undertaken

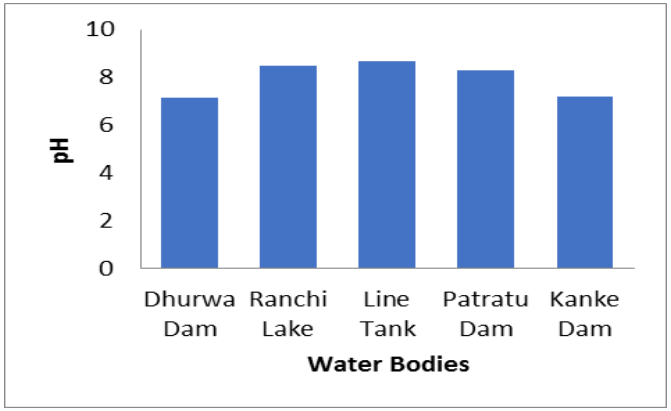

Figure 3: pH of water bodies

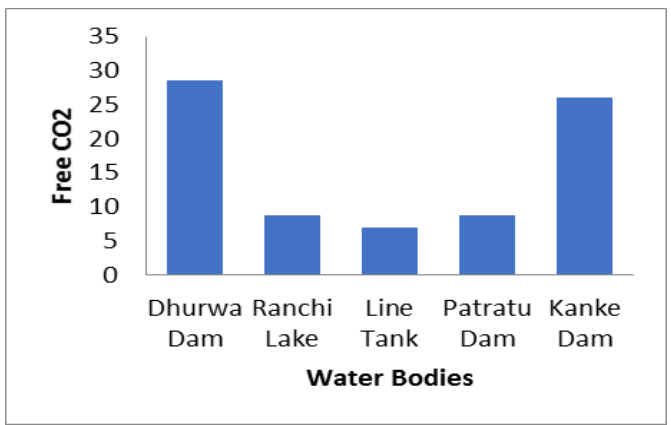

Figure 4: Free CO2 content in water bodies

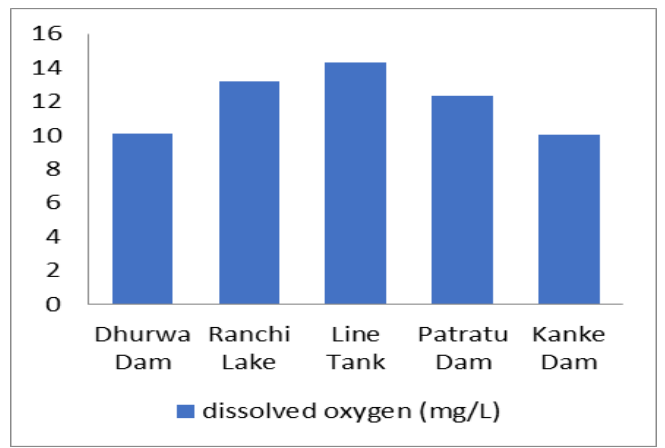

Figure 5: Dissolved oxygen content in water bodies

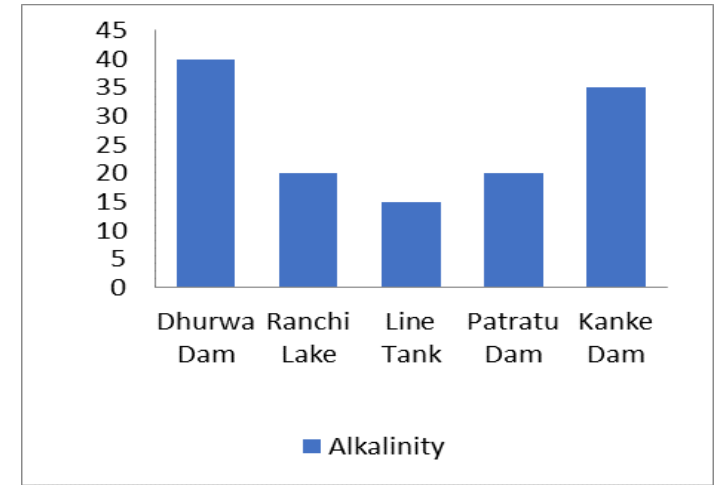

Figure 6: Alkalinity in water bodies

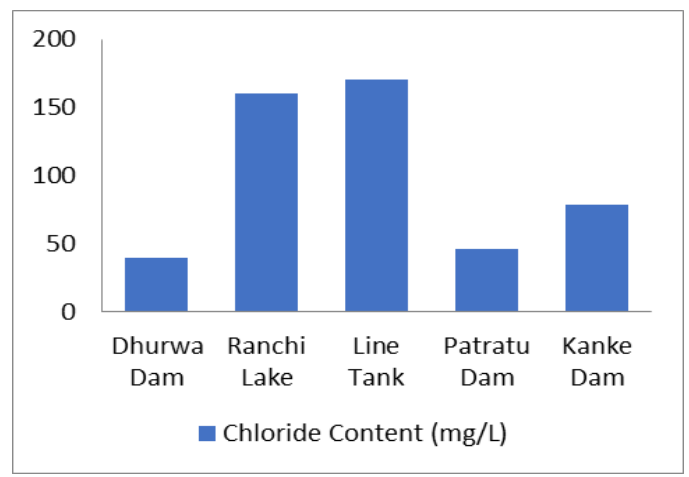

Figure 7: Chloride content in water bodies

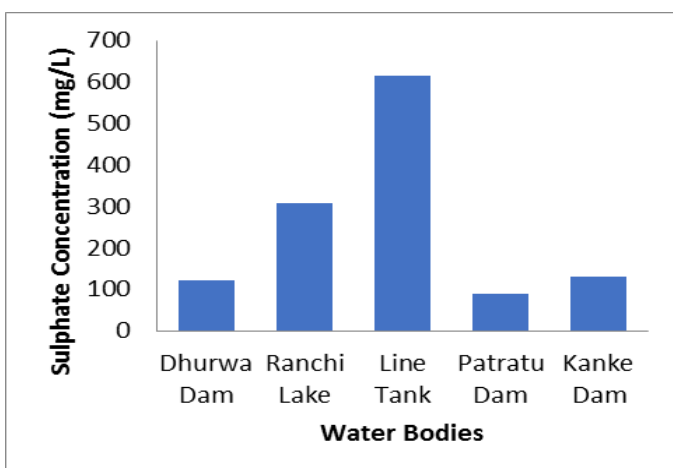

Figure 8: Sulphate content in water bodies

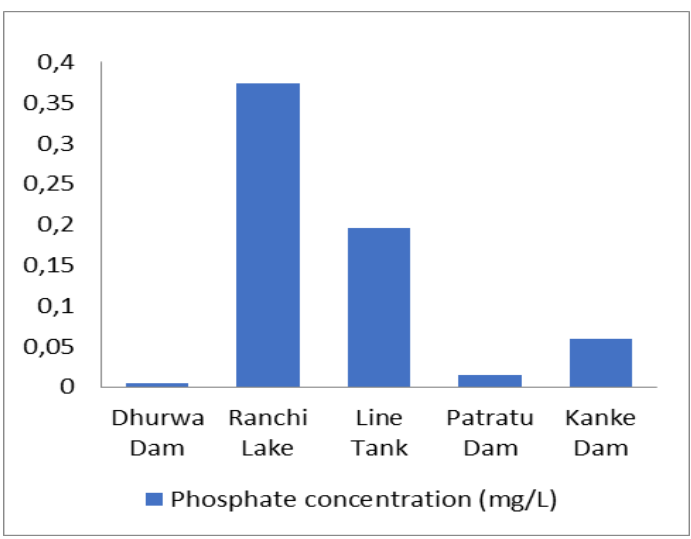

Figure 9: Phosphate content in water bodies 


\section{ACKNOWLEDGEMENTS}

The authors are thankful to the Principal, St. Xavier's College, Ranchi for providing all the possible infrastructure and motivation to carry on and complete this work. The authors further acknowledge the lab support extended by Mr. Julian Ekka, Lab Boy, Department of Zoology, St. Xavier's College, Ranchi during the entire period of the work.

\section{REFERENCES}

1. Alabaster, J. S. and R. Lloyd: Water quality criteria for freshwater fish. European Inland Fisheries Advisory Commission report (FAO). Buttersworth, London-Boston, p297 (1980).

2. Bisht, A. S., Ali, G., Rawat, D.S. and Pandey, N. N: Physico-chemical behaviour of three different water bodies of subtropical Himalayan region of India. Journal of Ecology and Natural Environment 5(12): 387-395 (2013)

3. Boyd, C.E: Water quality in ponds for aquaculture. Alabama Agricultural Experiment station, Auburn University, Auburn, Alabama, Birmingham Publishing Co., Birmingham, Alabama. P428 (1990).

4. Cocchetto D. M. and Levy, G: Absorption of orally administered sodium sulphate in humans. Journal of Pharmaceutical Sciences, 70: 331 - 333 (1981).

5. EFS (Environmental Fact Sheet): Sodium and chloride in drinking water (2010).

6. Fingl, E: Laxatives and cathartics. In: Gilman AG et al., eds. Pharmacological basis of therapeutics. New York, NY, MacMillan Publishing (1982).

7. Greenwood N. N., and Earnshaw, A: Chemistry of the elements. Oxford, Pregamon Press (1984).

8. Minnesota Pollution Control Agency: Nutrients: phosphorus, nitrogen sources, impact on water quality. Water quality/impared waters no. 3.22 (2008).

9. Morris, M. E. and Levy, G: Absorption of sulphate from orally administered magnesium sulphate in man. Journal of Toxicology - Clinical Toxicology 20: 107114. (1983).

10. Paterson DW et al.: Effects of sulphate in water on swine reproduction and young pig performance. Journal of Animal Science, 49:664 - 667 (1979).

11. Rim-Rukeh, A: Physico-Chemical and biological characteristics of stagnant water bodies (ponds and lakes) used for drinking and domestic purposes in Niger Delta, Nigeria. Journal of Environmental Protection, 4: 920-928 (2013).

12. The WQA Glossary of Terms, 31 March, 200. Retrieved 6 march, (2013).
13. UNEP: GEMS/Water data summary 19851987. Burlington, Ontario, Cannada center for inland waters; United Nations Environment Programme, Global Environment Monitoring system, GEMS/Water Programme office (1990).

14. US DHEW: Drinking water standards 1962. Washington, DC, US Department of Health, Education and Welfare, Public Health Service; US Government Printing Office (Publication No. 956) (1962).

15. Utah State University: Water Quality http://extension.usu.edu/waterquality/whatsin-your-water/ph ; retrieved 28 February, 2017.

16. WHO, 2003. Chloride in drinking water, Guidelines for drinking-water quality, $2^{\text {nd }} \mathrm{ed}$. Vol 2. Health criteria and other supporting information, World Health Organization, Geneva, 1996.

17. William, A. W. and Robert, M. D: Interactions of $\mathrm{pH}$, Carbon dioxide, Alkalinity and Hardness in fish ponds. SRAC publication 464: 1 - 4 (1992). 